\title{
¿DE QUÉ LADO ESTÁS?
}

THOMAS SHEEHAN

Hemato-oncología. Medicina, U. Glasgow

\begin{abstract}
RESUMEN. En la época moderna se prioriza uno de nuestros dos «lados», el «lado» analítico, a expensas de nuestro «lado» más sintético e intuitivo. Las nefastas consecuencias del énfasis en la razón instrumental que empezó en la época de Francis Bacon han sido descritoselocuentemente por varios pensadores importantes, incluyendo Max Weber, Martin Heidegger y Jürgen Habermas. El descuido de nuestras capacidades imaginativas puede empobrecer nuestras producciones artísticas y científicas y puede dificultar el acceso a la experiencia religiosa. La solución pasa por fomentar las habilidades que están siendo marginadas progresivamente en el sistema educativo actual en un intento de conseguir un sano equilibrio o armonía entre las distintas habilidades cognitivas del ser humano.
\end{abstract}

PALABRAS CLAVE: lado analítico, lado sintético, razón instrumental.

\section{Whose side are you on?}

ABSTRACT. The modern era is characterised by an emphasis on one of our two "sides", the analytic "side», at the cost of our more synthetic and intuitive "side». The negative consequences of the excessive dominance of instrumental reason have been eloquently described by various important thinkers, including Max Weber, Martin Heidegger and Jürgen Habermas. The neglect of our imaginative abilities could impoverish our artistic and scientific productions and hinder our access to the religious experience. The solution requires the promotion of those abilities which are being progressively marginalised in the current educational system, in an attempt to achieve a balance or harmony between the various cognitive capacities of the human being.

KEY WORDS: analytic side, synthetic side, instrumental reason.

\section{Cuestion de Equilibrio}

Una de las características más llamativas de la neurología humana es el alto nivel de especialización de nuestros dos hemisferios cerebrales. Los dos hemisferios están conectados entre sí por el corpus callosum y nuestro cerebro funciona de una manera global y coordinada. Sin embargo, es cierto que los dos hemisferios procesan la información de una manera radicalmente distinta.

El hemisferio izquierdo piensa lógica y analíticamente y lo hace paso a paso. Trabaja con datos ya establecidos y piensa utilizando palabras y números.

El hemisferio derecho, en cambio, es más intuitivo y sintético y piensa en imágenes y símbolos. Este hemisferio tiene una visión más global y holística del mundo. Es más imaginativo e inventivo y es capaz de crear ideas nuevas. Este hemisferio es el hemisferio responsable del manejo del lenguaje metafórico y juega un papel importante, aunque no exclusiva, en la apreciación estética y en las experiencias místicas. 
Para funcionar óptimamente y realizar todo nuestro potencial como seres humanos debemos utilizar los dos hemisferios de una manera coordinada y harmoniosa. Sin embargo, hay razones para dudar si nuestra época se caracteriza precisamente por un desarrollo equilibrado de nuestras capacidades.

Muchos filósofos y sociólogos han hablado de un desarrollo desigual de nuestras facultades mentales en la época moderna. Se puede debatir si este fenómeno tiene una base claramente neurocientífica o no pero, incluso si estuviéramos hablando en un sentido más metafórico que anatómico, parece indiscutible que la tendencia a fomentar uno de nuestros dos «lados» a expensas de la otra es una de las características más llamativas de nuestra época.

Hasta cierto punto, este desarrollo asimétrico, una hipertrofia de nuestra inteligencia instrumental, fue profetizado por Descartes en el siglo XVII, cuando dijo que el objetivo de la revolución científica ya empezando fue «conseguir nuestro dominio sobre la naturaleza y nuestra posesión de ella» (thus render ourselves the lords and possesers of nature) ${ }^{1}$.

Pensadores como Max Weber, Martin Heidegger y Jurgen Habermas nos han avisado sobre algunos de los efectos negativos de la mentalidad tecnocientífica.

Según el sociólogo Max Weber, el sueño de la razón ilustrada fue condenado de antemano al fracaso, debido a la visión parcial y estrecha que tenían los ilustrados sobre la naturaleza de la razón humana. En realidad, lo que hemos heredado de la Ilustración, según Weber, lejos de un paraíso terrenal, es una «jaula de hierro» y describe los habitantes de esta jaula como «especialistas sin espíritu, sensualistas sin corazón»².

El filósofo Habermas habla de una «patología de la modernidad... La realización deformada de la razón en el curso de la historia» ${ }^{3}$. La razón deformada de que habla Habermas es el énfasis excesivo en la razón instrumental, el uso de la razón humana no para profundizar en nuestro entendimiento de nosotros mismos y de la realidad en la que vivimos, sino para dominar y explotar la naturaleza y sus recursos naturales.

Martin Heidegger, también nos ha advertido sobre los peligros inherentes en la mentalidad tecnocientífica que domina nuestra época, una mentalidad que ve toda la naturaleza, incluso al final el hombre, como objetos utilizables o recursos a explotar. Ya no vemos el mundo como nuestro hogar, un hogar acogedor lleno de misterio y belleza, sino un sitio frio e incluso hostil al cual estamos arrojados.

Los grandes poetas también han sabido siempre que la poesía es el resultado de la actividad equilibrada de nuestros dos lados. El poeta Irlandés W.B Yeats habla de la «unidad del ser» como requisito imprescindible para la creación de una poesía verdadera. T.S. Eliot usa el término «sensibilidad no dividida» para expresar el mismo concepto y describe como el poema germina como un «embrión oscuro» en el subconsciente, «muy por debajo del nivel del pensamiento consciente» ${ }^{4}$. Luego,

1 Descartes, R., Discourse on the Method of Rightly Conducting one's Reason and Seeking Truth in the Sciences, Part 6, p. 24 www.earlymoderntexts.com/assets/pdfs/descartes

2 Weber, M., The Protestant Ethic and the Spirit of Capitalism, p.124 www.d.umn.edu/.../ The $\% 20$ Protestant $\% 20$ Ethic $\% 20$ and $\% 20$ the $\% 20$ Spiri

3 Bernstein, R., Habermas y La Modernidad, Cátedra, Madrid, 1988, p.17.

4 Stead, C. K., The New Poetic. Yeats to Eliot, Hutchison and Company, London, 1983, p. 129 
el material que crece así, más o menos fuera del control consciente del poeta, tiene que ser sometido a un proceso de estructuración y formalización, es decir, podemos decir que tiene que pasar a través del filtro del hemisferio izquierdo.

Incluso en la ciencia, aunque hay una tendencia a identificar la mentalidad científica con el hemisferio izquierdo, los grandes científicos, los científicos más creativos, usan su hemisferio derecho también, y mucho.

En su libro Las Revoluciones Cientificas, Thomas Kuhn habla de dos tipos de ciencia; una ciencia rutinaria practicada por científicos muy trabajadores pero no innovadores. Estos científicos amplían y extienden los conocimientos existentes, trabajando dentro del paradigma actual. En cambio, la ciencia revolucionaria la llevan a cabo los genios rompedores que cambian radicalmente el paradigma vigente. Si escuchamos las palabras de uno de estos científicos revolucionarios por excelencia, Albert Einstein, nos damos cuenta de la asombrosa similitud entre el proceso mental que él describe y los procesos mentales descritos por poetas o pintores:

«Los científicos grandes son artistas también. Todos los logros importantes de la ciencia tienen que nacer en un conocimiento intuitivo. Yo creo en la intuición y la inspiración».

En el campo de la medicina, debido a la enorme cantidad de datos que tienen que aprender los estudiantes hoy en día, gracias al impresionante progreso de la ciencia médica, existe el peligro de enfocar su educación sobre la parte técnica, a coste de la parte humana. Sin embargo, clínicos experimentados saben el importante papel que juega la intuición en el proceso diagnóstico y el efecto terapéutico de la relación humana entre paciente y médico.

En el campo del arte visual, una armonía entre nuestros dos lados permite al pintor crear una obra capaz de conmover al espectador tanto al nivel emocional como al nivel intelectual. Las consecuencias de la pérdida de este equilibrio o armonía se ven claramente en algunas corrientes del arte contemporáneo. El arte conceptual, un movimiento anticipado por las obras de Marcel Duchamp, es, como su nombre sugiere, un arte de una fría intelectualidad. La intención del famoso urinario de Duchamp es hacernos pensar sobre qué es lo que define una obra de arte... ¿se convierte un urinario en escultura por el mero hecho de colocarlo boca abajo en un museo? El arte conceptual a lo mejor nos hace pensar, pero no nos hace sentir.

En cuanto a la crisis actual de la fe religiosa, es posible que una de las barreras al acceso a la fe religiosa con que los jóvenes topan hoy en día sea el desarrollo asimétrico de sus capacidades cognitivas. De hecho, un estudio publicado en la revista «Science» en 2012 demuestra que, efectivamente, un enfoque excesivo en la razón instrumental parece reducir la receptividad a las experiencias y creencias religiosas.

En 1959, en su libro Las Dos Culturas, el físico y novelista Inglés C.P. Snow quejó del hecho de que el sistema educativo en aquel entonces privilegió a las artes liberales a expensas de las ciencias. En su día, puede que tuviera razón, pero parece que el péndulo ha ido al otro extremo ahora. Las humanidades están siendo cada vez más marginadas en aras del pragmatismo. Esta mentalidad ve las humanidades como un lujo de poca utilidad práctica comparado con las ciencias. Paradójicamente, es posible que esta obsesión utilitaria resulte contraproducente, incluso 
al nivel pragmático. Es posible que un sistema que prima las asignaturas técnicas y margina o excluye las humanidades sea capaz de producir muchos científicos rutinarios pero es más difícil que sea capaz de producir los científicos creativos, aquellos que generan los avances realmente originales y rompedores, puesto que la originalidad en la ciencia, igual que en el arte, depende en gran parte del hemisferio derecho. Pero la marginación de las humanidades en el sistema educativo puede tener consecuencias más preocupantes aún en lo que se refiere a la ciencia. Son precisamente los futuros científicos que más necesitan una formación humanística y, sobre todo, ética. La ciencia es demasiado poderosa y potencialmente peligrosa como para dejarla en manos de gente sin formación humana.

Tanto Habermas como Heidegger ven como una posible salida de la jaula de hierro descrita por Weber la cultivación de nuestras sensibilidades artísticas, empleando el término "artístico» en un sentido muy amplio. Necesitamos desarrollar una actitud radicalmente diferente hacia la naturaleza. Una manera potencialmente eficaz de conseguir este cambio radical de nuestra mentalidad sería cultivar nuestra sensibilidad estética para contrarrestar nuestra visión actual utilitarista y últimamente autodestructiva.

Quizás la misteriosa frase de Dostoievski, «La belleza salvará el mundo», contenga algo de verdad. Quizás la restauración de un sano equilibrio, una utilización más coordinada y global de todas nuestras capacidades cognitivas, con la consecuente recuperación de nuestras habilidades estéticas, pueda, efectivamente, salvar el mundo. Posiblemente nos permitiría practicar una medicina tecnológicamente avanzada y al mismo tiempo humana, producir obras de arte que valgan la pena, conseguir avances científicos realmente originales y abrir vías de acceso a la experiencia religiosa, vías actualmente cerradas para muchas personas.

Hemato-oncología (Medicina, U. Glasgow)

THOMAS SHEEHAN

ts@thinkphar.com

[Artículo aprobado para publicación en diciembre de 2016] 